\title{
Apigenin inhibits the proliferation and invasion of osteosarcoma cells by suppressing the Wnt/ $\beta$-catenin signaling pathway
}

\author{
XIAOFENG LIU ${ }^{1 *}$, LIUBING LI $^{1 *}$, LING LV $^{2}$, DONGMEI CHEN ${ }^{2}$, LIQIN SHEN $^{2}$ and ZONGGANG XIE ${ }^{1}$ \\ Departments of ${ }^{1}$ Orthopaedics and ${ }^{2}$ Oncology, The Second Affiliated Hospital of Soochow University, \\ Suzhou, Jiangsu 215004, P.R. China
}

Received July 2, 2014; Accepted October 6, 2014

DOI: $10.3892 /$ or.2015.4022

\begin{abstract}
Osteosarcoma (OS) is the most common type of bone cancer. Even with early diagnosis and aggressive treatment, the prognosis for OS is poor. In the present study, we investigated the proliferation and invasion inhibitory effect of apigenin on human OS cells and the possible molecular mechanisms involved. The cell viability of U2OS and MG63 human OS cell lines was detected by MTT assay. Cell cycle progression and invasion were assessed by flow cytometry and the Matrigel Boyden chamber assay, respectively, and the involvement of molecular mechanisms was examined by western blot analysis. We demonstrated that apigenin inhibited proliferation and reduced invasion in human OS cells, and downregulated the expression of $\beta$-catenin in OS cells. Furthermore, the inhibitory effect of apigenin on OS cells was reversed by overexpression of $\beta$-catenin, but enhanced by knockdown of $\beta$-catenin. Collectively, our results showed that apigenin inhibits the tumor growth of OS cells by inactivating Wnt $/ \beta$-catenin signaling. Therefore, apigenin is a promising chemotherapeutic agent that may be used in the treatment of human OS.
\end{abstract}

\section{Introduction}

Osteosarcoma (OS) is the most common form of malignant bone tumor and occurs most frequently in children and adolescents (1). It is highly aggressive, expands into the cortex of the bone, later erupts through the cortex into the soft tissues, and frequently leads to the development of micrometastases in the lung $(1,2)$. The primary treatment of osteosarcoma is the complete removal of tumor by wide excision with neoadjuvant and adjuvant chemotherapy (2). Despite progress

Correspondence to: Dr Liqin Shen or Dr Zonggang Xie, The Second Affiliated Hospital of Soochow University, 1055 Sanxiang Road, Jinchang, Suzhou, Jiangsu 215004, P.R. China

E-mail: liqin_shen@163.com

E-mail: zonggangxie@163.com

${ }^{*}$ Contributed equally

Key words: apigenin, osteosarcoma cells, proliferation, invasion, Wnt/ $\beta$-catenin signaling pathway in chemotherapy, the prognosis remains particularly poor for patients with recurrence and metastasis. This is largely attributed to a lack of complete understanding of the exact mechanisms for this malignancy. Therefore, further understanding of the molecular mechanisms of cancer progression and the development of new therapeutic tools based on these mechanisms are required.

The Wnt- $\beta$-catenin signaling pathway regulates a variety of genes that in turn orchestrate diverse cell functions such as morphogenesis, differentiation and proliferation (3). It also plays an important role in tumorigenesis and its aberrant activation has been associated with the pathogenesis of various tumors in human (4-6). It has been reported that salinomycin selectively targets OS stem cells possibly by inhibiting the Wnt/ $\beta$-catenin signaling pathway (7), which suggests that $\mathrm{Wnt} / \beta$-catenin may be important in OS.

Apigenin (4',5,7-trihydroxyflavone), a type of flavonoid, is widely contained in many fruits and vegetables such as oranges, tea, chamomile, onions and wheat sprouts (8). Findings of previous studies have demonstrated that apigenin inhibits the growth, invasion, and metastasis of tumors in vitro and in vivo (9-11). Results of a recent study showed that apigenin possesses anticancer properties for the induction of apoptosis in U2OS cells and inhibits the xenograft tumor growth (12). However, the precise molecular mechanisms of the anticancer effect of apigenin remain to be clarified.

In the present study, we investigated the effects of apigenin on OS cell proliferation and invasion. Furthermore, we investigated the molecular mechanisms of the anticancer effect of apigenin.

\section{Materials and methods}

Cell culture. The U2OS and MG63 human OS cell lines were obtained from the American Type Culture Collection. U2OS cells were maintained in McCoy's 5A medium, which was supplemented with $10 \%$ fetal bovine serum (FBS), penicillin $(100 \mathrm{U} / \mathrm{ml})$, and streptomycin $(100 \mu \mathrm{g} / \mathrm{ml})$ at $37^{\circ} \mathrm{C}$ with $5 \% \mathrm{CO}_{2}$. MG-63 cells were maintained in Eagle's minimum essential medium in $5 \% \mathrm{CO}_{2}$ at $37^{\circ} \mathrm{C}$.

MTT assay. Cell viability was determined by the MTT assay. In brief, cells were plated in 96-well plates at $3 \times 10^{4}$ cells per well. At 24, 48, 72, and $96 \mathrm{~h}$ post plating, the cells were treated 
with various concentrations of apigenin, and $\sim 20 \mu \mathrm{l}$ MTT reagent $(5 \mathrm{mg} / \mathrm{ml})$ was added into each well and then incubated at $37^{\circ} \mathrm{C}$ for $30 \mathrm{~min}$. To dissolve formazan crystals, culture medium was replaced with an equal volume of DMSO. After the mixture was agitated at room temperature for $10 \mathrm{~min}$, the absorbance of each well was determined at $490 \mathrm{~nm}$ using a microplate reader. Experiments were repeated in triplicate and the results are presented as the percentage of growth inhibition.

Cell cycle assay. The cells were seeded in 6-well plates and treated with various doses of apigenin or DMSO for $24 \mathrm{~h}$. The cells were harvested and resuspended in $200 \mu 1$ ice-cold phosphate-buffered saline (PBS), added to $4 \mathrm{ml}$ ice-cold ethanol and incubated on ice for $45 \mathrm{~min}$. After an additional washing, the cells were incubated with RNase A $(20 \mu \mathrm{g} / \mathrm{ml})$ at $37^{\circ} \mathrm{C}$ for $30 \mathrm{~min}$, stained with propidium iodide $(100 \mu \mathrm{g} / \mathrm{ml}$; Sigma-Aldrich, St. Louis, MO, USA) for $10 \mathrm{~min}$, and analyzed with flow cytometry.

Cell invasion assay. Cell invasion was measured using a modified Matrigel Boyden chamber (BD Bioscience, Bedford, MA, USA) (13). The cells were treated with various concentrations of apigenin or pretreatment of cells with apigenin was treated with overexpression- $\beta$-catenin or siRNA- $\beta$-catenin for $4 \mathrm{~h}$, and then seeded in the upper compartment. The medium including $10 \%$ FBS was added into the lower compartment. After $48 \mathrm{~h}$, the cells that filtered through the lower side of the membrane were stained with hematoxylin and eosin and quantified by counting five high-power fields in the center of each well.

Quantitative PCR. Total RNA was extracted from the cells using TRIzol reagent (Invitrogen, Carlsbad, CA, USA) according to the manufacturer's instructions. Quantitative PCR (qPCR) reactions were performed on the Bio-Rad iQ5 real-time thermal cyclers using SYBR ${ }^{\circledR}$ Premix Ex Taq ${ }^{\mathrm{TM}}$ II kit (Takara, Dalian, China). The specific primers used were: $\beta$-catenin sense: 5'-TGAGGACAAGC CACAAGATTAC-3' and antisense: 5'-TCCACCAGAGTGAA AAGAACG-3'; $\beta$-actin sense: 5'-GATCATTGCTCCTCCTG AGC-3' and antisense: 5'-ACTCCTGCTTGCTGATCCAC-3'. These primers were synthesized by Sangon Biotech Co., Ltd. (Shanghai, China). The PCR procedure was as follows: polymerase activation for $30 \mathrm{sec}$ at $95^{\circ} \mathrm{C}, 40$ cycles of amplification each consisting of $95^{\circ} \mathrm{C}$ for $5 \mathrm{sec}, 60^{\circ} \mathrm{C}$ for $20 \mathrm{sec}$, and 1 cycle of dissociation consisting of $95^{\circ} \mathrm{C}$ for $15 \mathrm{sec}, 60^{\circ} \mathrm{C}$ for $30 \mathrm{sec}$ and $95^{\circ} \mathrm{C}$ for $15 \mathrm{sec}$. Relative quantification of gene expression was performed using the $2^{-\Delta \Delta \mathrm{Ct}}$ method and with $\beta$-actin mRNA as an internal control. The reactions were performed in triplicate.

Western blot analysis. The cells were sonicated with lysis buffer (PBS with 1\% Triton X-100 and protease inhibitors). The cell lysate supernatants were harvested by centrifugation at $10,000 \mathrm{rpm}$ for $10 \mathrm{~min}$ at $4^{\circ} \mathrm{C}$. Protein concentrations of the cell supernatants were evaluated and measured by BCA Protein Assay kit. An equal amount of the proteins from each extract was separated on a SDS-PAGE, and transferred electrophoretically using PVDF membranes. The membranes were then blocked by $5 \%$ non-fat dry milk in PBST [PBS with $0.1 \%$ Tween-20, $(\mathrm{pH} 7.6)]$ for $1 \mathrm{~h}$ at room temperature and probed overnight with appropriate primary antibodies (anti- $\beta$-catenin

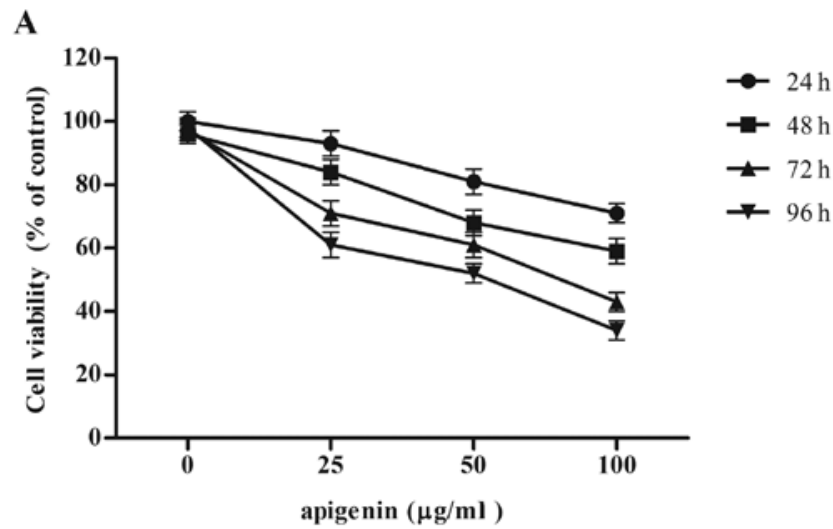

B

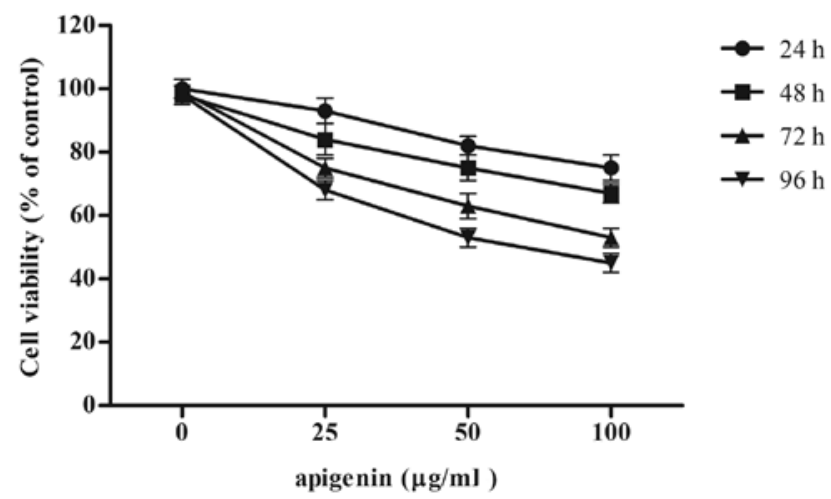

Figure 1. Apigenin inhibits OS cell proliferation. (A) U2OS and (B) MG63 cells were treated with apigenin $(0-100 \mu \mathrm{g} / \mathrm{ml})$ for $24,48,72$ and $96 \mathrm{~h}$, and cell viability was detected using MTT assay. Results are presented as means \pm SD of three independent experiments.

or anti- $\beta$-actin) diluted in PBST at $4^{\circ} \mathrm{C}$. The membranes were rinsed three times with PBST and incubated with appropriate secondary antibodies diluted in PBST for $1 \mathrm{~h}$ at room temperature. The membranes were then rinsed three times with PBST at room temperature for $10 \mathrm{~min}$, and the blots were visualized by enhanced chemiluminescence using Kodak X-omat LS film (Eastman Kodak, Rochester, NY, USA). The protein level quantification was carried out by ImageJ (Molecular Dynamics, Sunnyvale, CA, USA).

Plasmid construction and transfection. Total RNA from U2OS cells was extracted using TRIzol reagent (Invitrogen, Carlsbad, CA, USA), according to the manufacturer's instructions. The cDNA was synthesized by reverse transcription of total RNA, using the Prime Script ${ }^{\circledR}$ RT reagent kit (Takara, Dalian, China) with oligo-dT primers, according to the manufacturer's instructions. The open reading frame of $\beta$-catenin cDNA was subsequently cloned into the pcDNA3.1 vector (Invitrogen) to construct the recombinant pcDNA3.1- $\beta$-catenin expression vector. In addition, lentivirus-mediated siRNA constructs were designed by Shanghai Genechem (Shanghai, China). The sequences corresponding to the siRNA of $\beta$-catenin were: sense: 5'-UGGUUGCCUUGCUCAAdTdT-3' and antisense: 5'-UUGUUGAGCAAGGCAACCAdTdT-3'. For the in vitro transfection, cells $\left(5 \times 10^{4}\right)$ were seeded in each of the 24-well microplates, grown for $24 \mathrm{~h}$ to reach $50 \%$ confluency, and then 
A
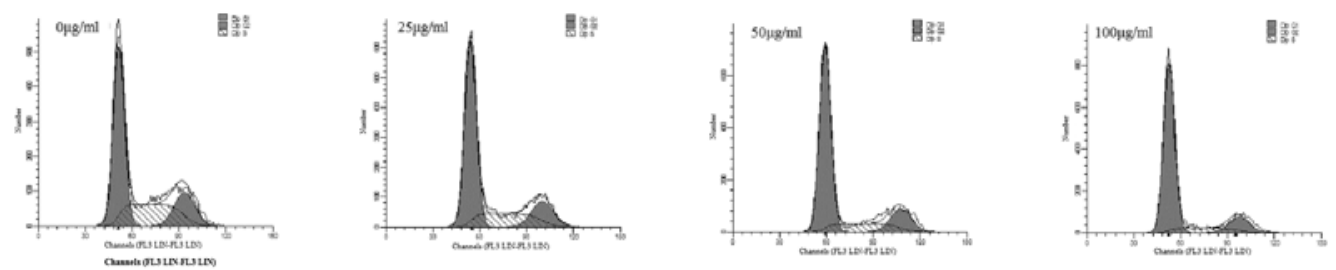

B

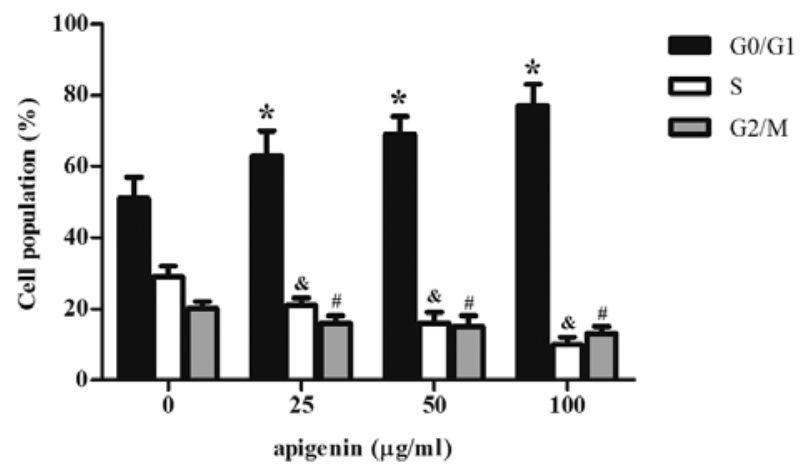

C
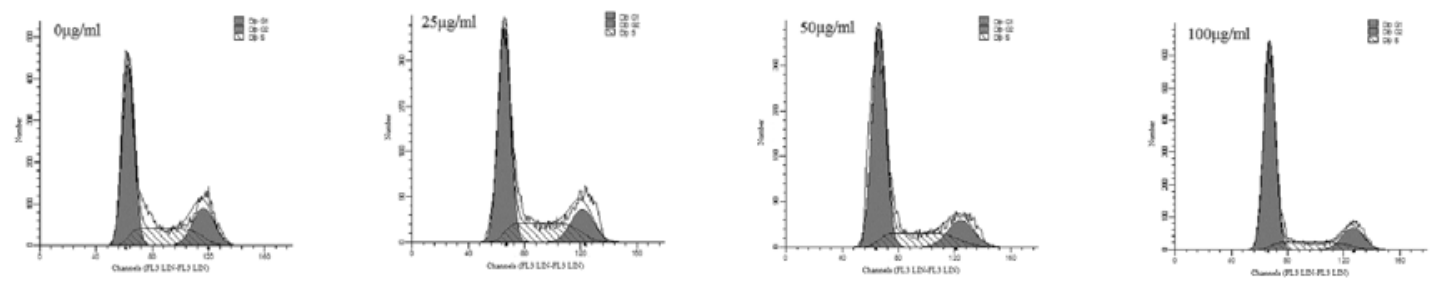

D

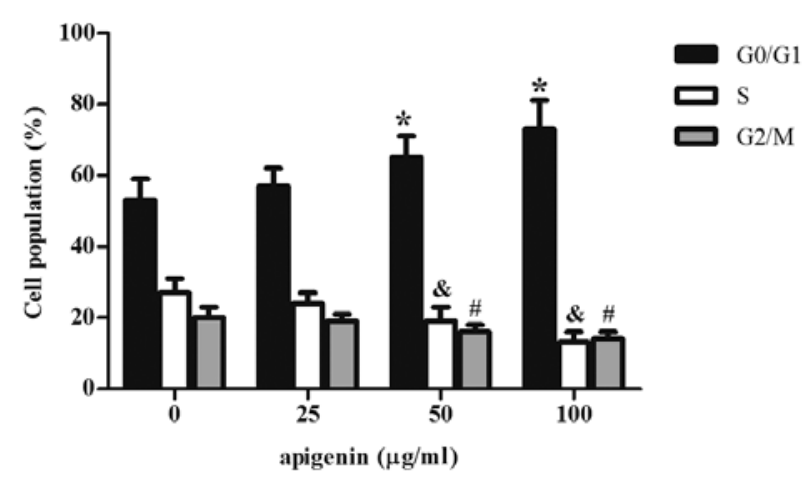

Figure 2. Apigenin induces OS cell cycle arrest. (A) U2OS and (C) MG63 cells were treated with increasing doses of apigenin or vehicle DMSO for $24 \mathrm{~h}$. Cell-cycle distributions were analyzed by flow cytometry with PI staining. Percentages of cell cycle distribution in (B) U2OS and (D) MG63 cells are presented as an histogram graph. All experiments were repeated at least three times. ${ }^{*} \mathrm{P}<0.05,{ }^{\circledR} \mathrm{P}<0.05,{ }^{n} \mathrm{P}<0.05$, compared with control group.

incubated with a mixture of overexpression- $\beta$-catenin or siRNA- $\beta$-catenin and Lipofectamine 2000 reagent (Invitrogen) in $100 \mu \mathrm{l}$ serum-free Opti-Mem according to the manufacturer's instructions. The transfection efficiency was examined by qPCR and western blotting.

Statistical analysis. Data were presented as the mean \pm standard error of the mean (SEM). The differences between the control and apigenin-treated groups were compared by Dunnett's test subsequent to ANOVA. $\mathrm{P}<0.05$ was considered to indicate a statistically significant difference. All the experiments were repeated at least three times.

\section{Results}

Cytotoxicity of apigenin on OS cells. We measured the effect of apigenin on OS cell proliferation by MTT assay. As shown in Fig. 1, there was a marked decrease in the proliferation of cells with increasing doses of apigenin. Apigenin inhibited cell proliferation in a time- and dose-dependent manner in 

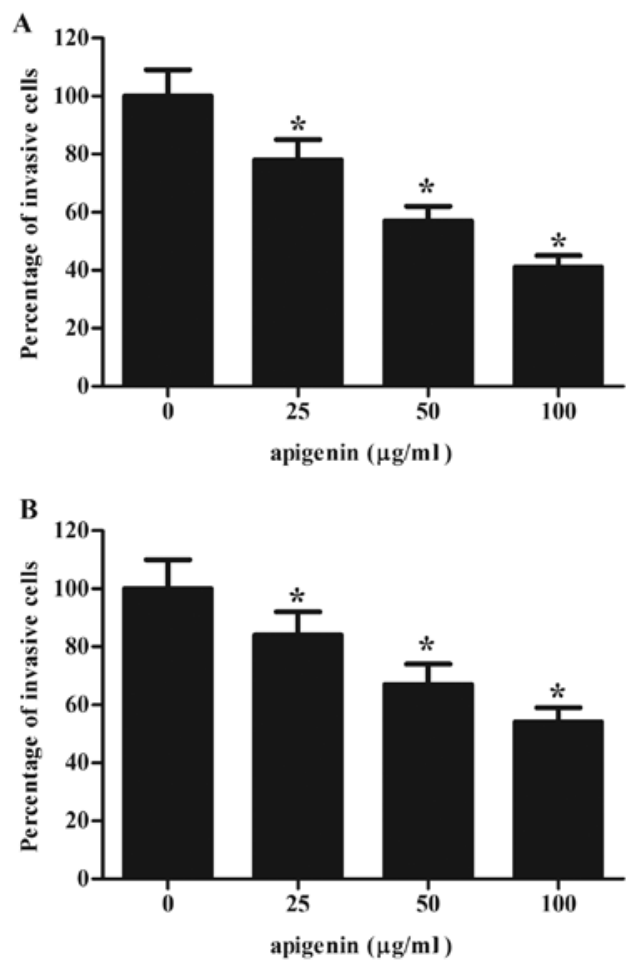

Figure 3. Apigenin treatment inhibits OS cell invasion. Invasion was evaluated using Matrigel Boyden chambers. The number of migration cells through the Matrigel-coated membrane was decreased in (A) U2OS and (B) MG63 cells treated with apigenin. Data are presented as mean \pm SD. All experiments were repeated at least three times. ${ }^{*} \mathrm{P}<0.05$ compared to the control group.

the U2OS and MG-63 cells. These findings suggested that apigenin was able to inhibit the proliferation and survival of U2OS and MG-63 cells.

Effect of apigenin on OS cell cycle. We investigated the effect of apigenin on the OS cell cycle. As shown in Fig. 2, compared to the control group, apigenin-treated cells exhibited obvious cell arrest in the G0/G1 phase after $24 \mathrm{~h}$. The increase in the G0/G1 cell population was accompanied by a concomitant decrease in the population in the $\mathrm{S}$ and $\mathrm{G} 2 / \mathrm{M}$ phases of the cell cycle. These results indicated that the decreased proliferation in apigenin-treated OS cells is at least partially a result of the cell cycle arrest by apigenin.

Effect of apigenin on OS cell invasion. Provided the development of metastasis is highly dependent on cell migration and invasion (14), we investigated the impact of apigenin on OS cell invasion by a modified Matrigel Boyden chamber. As shown in Fig. 3, after treatment with apigenin, the number of invaded cells was significantly decreased, as compared with the control group. These findings indicate that apigenin inhibited the invasion of U2OS and MG-63 cells. However, U2OS is more sensitive for apigenin treatment, which was selected for the subsequent experiments.

Apigenin inhibited the expression of $\beta$-catenin in OS cells. We investigated a potential mechanism for apigenin-mediated OS cell proliferation and invasion. It is well known that the

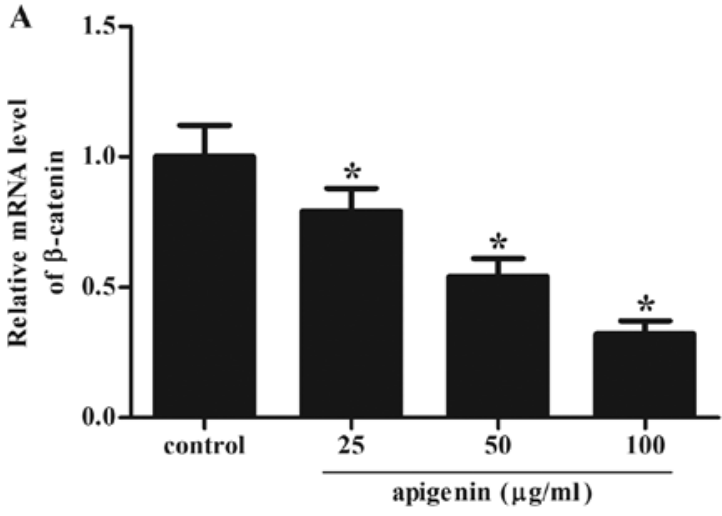

B

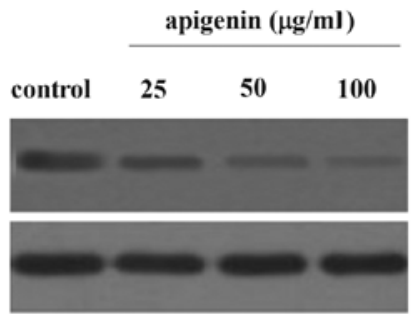

Figure 4. Effect of apigenin on expression of $\beta$-catenin in U2OS cells. (A) Representative images of relative mRNA level of $\beta$-catenin treated with various concentrations of apigenin. (B) Representative western blots of $\beta$-catenin. The expression levels of proteins were normalized based on the $\beta$-actin levels. Data are presented as mean \pm SD. All experiments were repeated at least three times. ${ }^{*} \mathrm{P}<0.05$ compared to the control.

Wnt/ $\beta$-catenin signaling pathway modulates cancer cell proliferation, apoptosis and metastasis, therefore, we examined whether apigenin was able to inhibit the expression of $\beta$-catenin. As shown in Fig. 4A, as compared with the control group, obvious downregulation of $\beta$-catenin mRNA was identified in OS cells when treated with apigenin. Simultaneously, the corresponding decrease in $\beta$-catenin protein levels was also confirmed by western blotting (Fig. 4B). These data suggested that apigenin inhibited the expression of $\beta$-catenin in OS cells.

Overexpression of $\beta$-catenin reversed the inhibitory effect of apigeninon OS cells. The role of $\beta$-catenin in apigenin-mediated phenotypes was then evaluated. In this study, we found that the mRNA and protein levels of $\beta$-catenin in the overexpression- $\beta$ catenin-transfected group were significantly higher than those in the mock group (Fig. 5A and B). We also examined whether overexpression of $\beta$-catenin reversed the inhibitory effect of apigenin on OS cells. As expected, following treatment with $\beta$-catenin overexpression, the inhibitory effect of apigenin on proliferation and invasion was significantly reversed in OS cells, as compared with the mock group (Fig. 5C and D).

Knockdown of $\beta$-catenin enhanced apigenin-inhibited proliferation and invasion in OS cells. To confirm the role of $\beta$-catenin in OS cell proliferation and invasion, a siRNA experiment was performed in OS cells. The mRNA and protein levels of $\beta$-catenin in the siRNA- $\beta$-catenin-transfected group were significantly lower than those in the mock group (Fig. 6A and B). We also examined the effect of knockdown of $\beta$-catenin on the activity of apigenin, including the inhibition of cell proliferation and invasion. The results showed that siRNA- $\beta$ - 
A

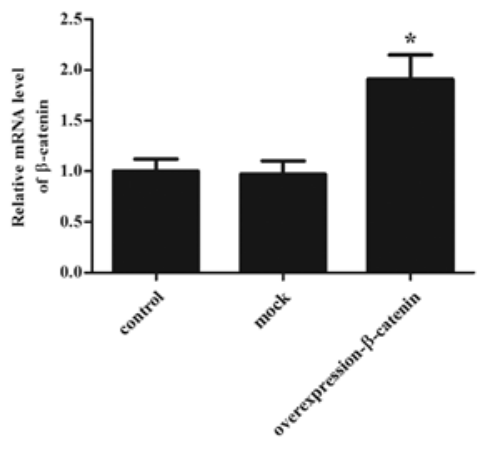

C

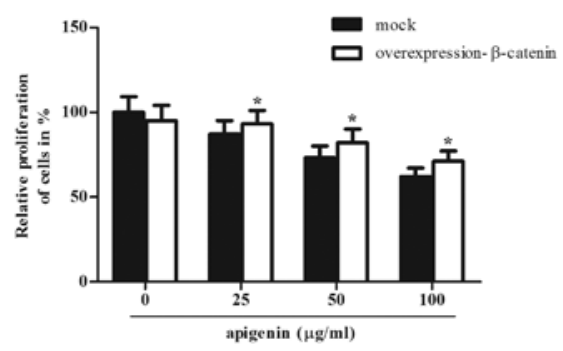

B

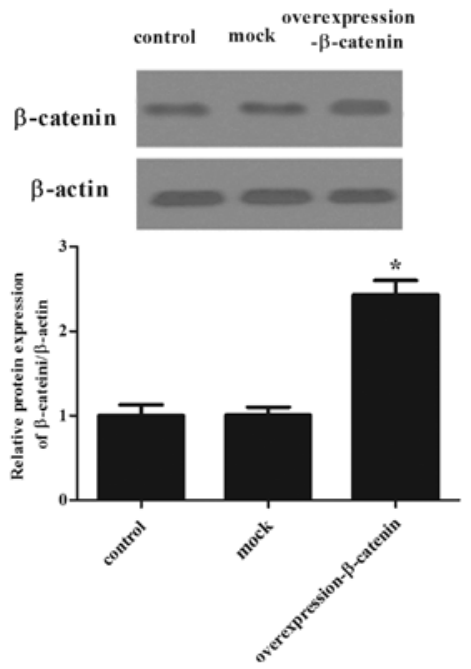

D

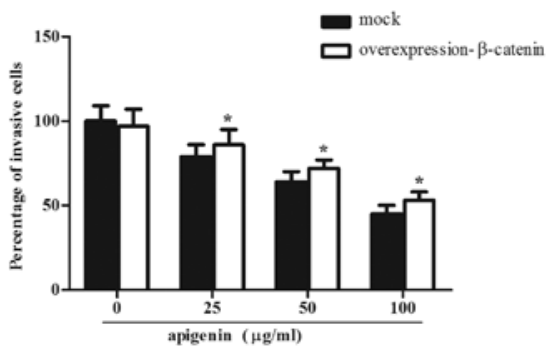

Figure 5. Overexpression of $\beta$-catenin reverses the inhibitory effect of apigenin on OS cells. (A) Representative images of relative mRNA level of $\beta$-catenin treated with overexpression- $\beta$-catenin. (B) Representative western blots of overexpression- $\beta$-catenin. (C) Overexpression- $\beta$-catenin reversed apigenin-inhibited OS cell proliferation. (D) Overexpression- $\beta$-catenin reversed apigenin-inhibited OS cell invasion. ${ }^{*} \mathrm{P}<0.05$, compared with the mock group.

A

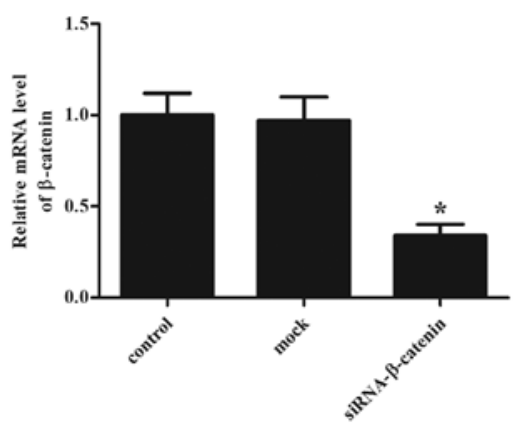

C

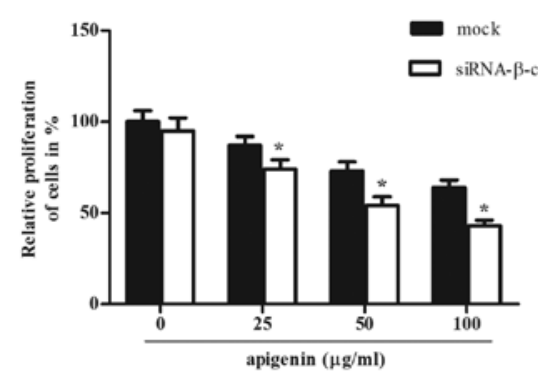

B

B control mock $\underset{\beta-\text { catenin }}{\text { siRNA- }}$

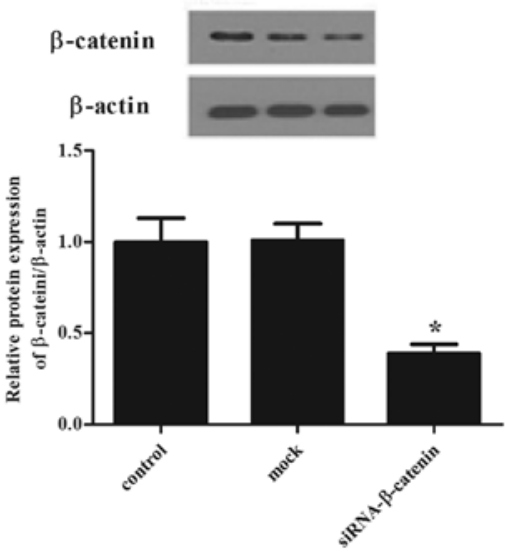

D

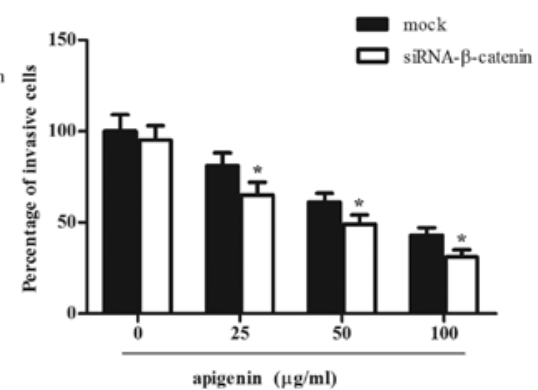

Figure 6. Knockdown of $\beta$-catenin enhances apigenin-inhibited proliferation and invasion in OS cells. (A) mRNA and (B) protein levels of $\beta$-catenin in the siRNA- $\beta$-catenin-transfected group. (C) siRNA- $\beta$-catenin enhanced apigenin-inhibited OS cell proliferation. (D) siRNA- $\beta$-catenin enhanced apigenin-inhibited OS cell invasion. ${ }^{*} \mathrm{P}<0.05$, compared with the mock group. 
catenin obviously potentiated apigenin-induced proliferation inhibition (Fig. 6C). Moreover, siRNA- $\beta$-catenin significantly promoted apigenin-induced invasion inhibition (Fig. 6D). The results indicated that knockdown of $\beta$-catenin enhanced apigenin-inhibited proliferation and invasion in OS cells.

\section{Discussion}

Apigenin, a naturally occurring plant flavone that is abundantly present in common fruits and vegetables, is a bioactive flavonoid shown to possess anticancer properties. However, the molecular mechanism involved in the anticancer effect of apigenin in OS has yet to be elucidated. In the present study, we found that apigenin exhibits anti-proliferative and antiinvasive activity in OS cells. In addition, apigenin was able to downregulate the expression of $\beta$-catenin. Overexpression of $\beta$-catenin reversed the inhibitory effect of apigenin on OS cells, and knockdown of $\beta$-catenin enhanced apigenininhibited proliferation and invasion in OS cells.

Findings of previous studies have demonstrated that apigenin inhibited pancreatic cancer cell proliferation in a dose-dependent manner (11), and it also inhibited the migration and invasion of A2780 human ovarian cancer cells (15). Furthermore, OS tumorigenesis is often associated with tumor cell proliferation and invasion (16). Therefore, we investigated the effects of apigenin on OS cell proliferation and invasion. Consistent with previous studies, results of the present study demonstrate that apigenin inhibited the proliferation and invasion of OS cells in vitro.

The Wnt pathway consists of highly conserved secreted ligands that bind cell-surface receptors known as frizzled proteins and lipoprotein receptor-related proteins (LRPs). In the presence of Wnt signaling, $\beta$-catenin is accumulated in the cytosol, translocated into the nucleus, and forms a complex with the lymphocyte enhancer factor (LEF)/T-cell factor (TCF) family of transcription factors to activate target genes (17). $\beta$-catenin was shown to promote tumorigenesis, progression, and invasion in cancers $(6,18,19)$. For example, it is overexpressed in human glioblastoma, and knockdown of $\beta$-catenin inhibits glioblastoma cell proliferation and invasive ability, and induces apoptotic cell death (20). Furthermore, the intratumoral introduction of siRNA targeting $\beta$-catenin into established subcutaneous gliomas also delayed tumor growth. In OS, several secreted protein families modulate the Wnt/ $\beta$-catenin signaling, including secreted Frizzled-related proteins (sFRPs), Wnt inhibitory protein (WIF), Dickkopf proteins, sclerostin, and small molecules. It was shown that the Wnt inhibitory factor 1 is epigenetically silenced in human osteosarcoma, and its disruption accelerates osteosarcoma development in mice (21). In a recent study, it was shown that a high $\beta$-catenin level in OS samples is positively correlated with lung metastasis (22). Therefore, we hypothesize that apigenin downregulates the expression of $\beta$-catenin. In this study, we found that apigenin downregulates the expression of $\beta$-catenin in OS cells.

The canonical Wnt- $\beta$-catenin signaling pathway is a key component of normal skeletal development and disease. Aberrant activation of the Wnt- $\beta$-catenin signaling pathway plays a critical role in OS pathogenesis (23). It has been reported that a decreased $\beta$-catenin expression can suppress matrix metalloproteinase 14 (MMP14) expression, thereby resulting in suppression of the invasion and motility of MG-63 cells (24). In this study, we found that overexpression of $\beta$-catenin reversed the inhibitory effect of apigenin on OS cells, and knockdown of $\beta$-catenin enhanced apigenininhibited proliferation and invasion in OS cells. These results support the hypothesis that $\beta$-catenin is involved in OS cell proliferation and invasion in response to apigenin.

In conclusion, the present study suggests that apigenin is particularly effective in inhibiting proliferation and invasion of OS cells by suppressing the Wnt/ $\beta$-catenin signaling pathway. Therefore, apigenin may be a chemopreventive and/or therapeutic agent in the prevention of OS cancer.

\section{References}

1. Bacci G, Longhi A, Versari M, Mercuri M, Briccoli A and Picci P: Prognostic factors for osteosarcoma of the extremity treated with neoadjuvant chemotherapy: 15 -year experience in 789 patients treated at a single institution. Cancer 106: 1154-1161, 2006.

2. Ferguson WS and Goorin AM: Current treatment of osteosarcoma. Cancer Invest 19: 292-315, 2001.

3. Clevers H: Wnt/beta-catenin signaling in development and disease. Cell 127: 469-480, 2006.

4. Polakis P: Wnt signaling and cancer. Gene Dev 14: 1837-1851, 2000.

5. Uematsu K, He B, You L, Xu Z, McCormick F and Jablons DM: Activation of the Wnt pathway in non small cell lung cancer: evidence of dishevelled overexpression. Oncogene 22: 7218-7221, 2003.

6. Hatsell S, Rowlands T, Hiremath M and Cowin P: Beta-catenin and Tcfs in mammary development and cancer. J Mammary Gland Biol Neoplasia 8: 145-158, 2003.

7. Tang QL, Zhao ZQ, Li JC, Liang Y, Yin JQ, Zou CY, Xie XB, Zeng YX, Shen JN and Kang T: Salinomycin inhibits osteosarcoma by targeting its tumor stem cells. Cancer Lett 311: 113-121, 2011.

8. Patel D, Shukla S and Gupta S: Apigenin and cancer chemoprevention: Progress, potential and promise (Review). Int $J$ Oncol 30: 233-245, 2007.

9. Wang W, Heideman L, Chung CS, Pelling JC, Koehler KJ and Birt DF: Cell-cycle arrest at G2/M and growth inhibition by apigenin in human colon carcinoma cell lines. Mol Carcinog 28: 102-110, 2000.

10. Way TD, Kao MC and Lin JK: Apigenin induces apoptosis through proteasomal degradation of HER2/neu in HER2/neuoverexpressing breast cancer cells via the phosphatidylinositol 3-kinase/Akt-dependent pathway. J Biol Chem 279: 4479-4489, 2004.

11. Ujiki MB, Ding X-Z, Salabat MR, Bentrem DJ, Golkar L, Milam B, Talamonti MS, Bell RH, Iwamura T and Adrian TE: Apigenin inhibits pancreatic cancer cell proliferation through G2/M cell cycle arrest. Mol Cancer 5: 76, 2006.

12. Lin CC, Chuang YJ, Yu CC, Yang JS, Lu CC, Chiang JH, Lin JP, Tang NY, Huang AC and Chung JG: Apigenin induces apoptosis through mitochondrial dysfunction in U-2 OS human osteosarcoma cells and inhibits osteosarcoma xenograft tumor growth in vivo. J Agric Food Chem 60: 11395-11402, 2012.

13. Liu X, Zhang X, Xiang J, Lv Y and Shi J: miR-451: Potential role as tumor suppressor of human hepatoma cell growth and invasion. Int J Oncol 45: 739-745, 2014.

14. Jaffe N: Osteosarcoma: review of the past, impact on the future. The American experience. Cancer Treat Res 152: 239-262, 2009.

15. Hu XW, Meng D and Fang J: Apigenin inhibited migration and invasion of human ovarian cancer A2780 cells through focal adhesion kinase. Carcinogenesis 29: 2369-2376, 2008.

16. Yan K, Gao J, Yang T, Ma Q, Qiu X, Fan Q and Ma B: MicroRNA-34a inhibits the proliferation and metastasis of osteosarcoma cells both in vitro and in vivo. PLoS One 7: e33778, 2012.

17. Logan CY and Nusse R: The Wnt signaling pathway in development and disease. Annu Rev Cell Dev Biol 20: 781-810, 2004. 
18. Brabletz T, Jung A, Dag S, Hlubek F and Kirchner T: Beta-catenin regulates the expression of the matrix metalloproteinase-7 in human colorectal cancer. Am J Pathol 155: 1033-1038, 1999.

19. Li YJ, Wei ZM, Meng YX and Ji XR: Beta-catenin up-regulates the expression of cyclinD1, c-myc and MMP-7 in human pancreatic cancer: relationships with carcinogenesis and metastasis. World J Gastroenterol 11: 2117-2123, 2005.

20. Pu P, Zhang Z, Kang C, Jiang R, Jia Z, Wang G and Jiang $H$ : Downregulation of Wnt 2 and beta-catenin by siRNA suppresses malignant glioma cell growth. Cancer Gene Ther 16: 351-361, 2009.

21. Kansara M, Tsang M, Kodjabachian L, Sims NA, Trivett MK, Ehrich M, Dobrovic A, Slavin J, Choong PF, Simmons PJ, Dawid IB and Thomas DM: Wnt inhibitory factor 1 is epigenetically silenced in human osteosarcoma, and targeted disruption accelerates osteosarcomagenesis in mice. J Clin Invest 119: 837-851, 2009.
22. Kidani T, Nakamura A, Kamei S, Norimatsu Y, Miura $\mathrm{H}$ and Masuno H: Overexpression of cytoplasmic $\beta$-catenin inhibits the metastasis of the murine osteosarcoma cell line LM8. Cancer Cell Int 14: 31, 2014.

23. Lin CH, Ji T, Chen CF and Hoang BH: Wnt signaling in osteosarcoma. Adv Exp Med Biol 804: 33-45, 2014.

24. Zhang F, Chen A, Chen J, Yu T and Guo F: SiRNA-mediated silencing of beta-catenin suppresses invasion and chemosensitivity to doxorubicin in MG-63 osteosarcoma cells. Asian Pac J Cancer Prev 12: 239-245, 2011. 